\title{
Variations introduced in sorghum through pollination with maize
}

\author{
K. B. R. S. Visarada* \\ Indian Institute of Millets Research (formerly Directorate of Sorghum Research), Rajendranagar, Hyderabad 500 030 , India
}

\begin{abstract}
Repeated pollinations of sorghum lines with pregerminated pollen from inbred maize lines resulted in large de novo variation in $\mathrm{F}_{2}$. Though the phenotypes of all the plants were biased towards sorghum, traits of maize such as leaf anatomy and morphology were observed in some of the crosses. RAPD marker analysis of the derivatives in advanced stages of generation showed maize-specific bands. It was interesting to note that diverse types of sorghum emanated from a single cross. We present the stable inheritance of variation, thus introducing agronomically superior, novel, pre-breeding lines for sorghum crop improvement through incompatible pollinations.
\end{abstract}

Keywords: De novo variation, intergeneric hybridization, maize, pollination, sorghum.

INTERGENERIC hybridization provides material useful for practical plant breeding programmes, for conducting genetic studies on plant traits and for studying the possible effects of alien introgression on the recipient genome. It plays a key role to generate extensive stochastic genomic and epigenomic variations that can be translated into phenotypic novelties. Crosses between incompatible species lead to introduction of new variation in the gene pool through genetic and epigenetic changes that contravene Mendelian principles. Intergeneric hybridization of incompatible species is employed for the creation of stable genetic variation for the crop improvement in rice and sugarcane ${ }^{1-5}$.

Inter-crossing between sorghum and maize has received attention since 1932 by many groups with seed set reported by some, but further developments are not available ${ }^{6}$. Most of the reports are limited to cytological and molecular evidence of inter-crossing and not to the extent of field evaluation in sorghum. Laurie and Bennett $^{7}$ reported the inhibition of growth of maize pollen tubes in the stigmas of sorghum as the inhibiting factor for crossing sorghum and maize. The objective was to understand subsequent developments after crosses between syntenic species like sorghum and maize with pollen intervention. The results have provided valuable material for crop improvement and for molecular study to understand how different types like sweet, forage and

*e-mail: visarada@millets.res.in grain exist in sorghum, though they share a common genome. In the present study, we have advanced the progeny of sorghum $\times$ maize crosses, confirmed the stability of variations and established the competency of these variants compared to elite genotypes.

\section{Materials and methods}

The plant material used in the study included four inbred lines of maize (CM118, CM130, CM208, and CM211) and nine cytoplasmic male sterile (CMS) lines of sorghum. Maize lines were obtained from the Maize Research Station, Professor Jayashankar Telangana State Agricultural University, Hyderabad, India. Nine male sterile lines of sorghum, viz. 27A, 126A, 296A, 356A, C43, MR750A $2, \mathrm{~A}_{2} 7, \mathrm{~A}_{3} 8$ and $\mathrm{A}_{4} 9$, were obtained from the Germplasm Unit, Indian Institute of Millets Research (formerly Directorate of Sorghum Research), Hyderabad. During the post-rainy season in 2008, all the sorghum CMS lines were sown at $15 \mathrm{~d}$ interval in pots for synchronization of flowering with maize inbred lines. After emerging from the boot leaf and 1-2 days before the opening of florets, the sorghum panicles were covered with paper bags to avoid any cross-pollination. Each experiment was carried out on flower heads which were protected from foreign pollen by bagging. Lower rachi of these panicles were cut gently leaving top florets to ensure good seed set. Initially, pollen germination of maize lines was standardized using four different pollen germination media (PGM1-PGM4) ${ }^{8}$. Percentage of pollen grains germinated and length of the pollen tube were examined under a microscope to optimize the best medium. Pollen grains from maize were collected in a petri plate through dusting of florets or gentle squash of mature anthers. They were immediately carried to the recipient sorghum plant and 1-2 drops of PGM-2 were added to the pollen grains in the petri plate, and gently mixed with a soft brush. Paper bag on the recipient sorghum plant was removed and immediately the pregerminated pollen was placed on the stigma of sorghum florets with a soft paintbrush. Sorghum panicle was covered immediately with the same paper bag. The above process was initiated one or two days before opening of sorghum florets and emergence of the stigma. This procedure was repeated 5-6 days on every plant with the 
pollen from the same maize line. Each male sterile sorghum line was repeatedly pollinated with pre-germinated pollen from one of the four inbred lines of maize, viz. CM118, CM130, CM208 and CM211. Seeds were allowed to mature on the sorghum plant and $F_{1}$ seeds were harvested. In some cases, the seeds were shrivelled and embedded deep in the glumes. These were carefully taken out with hand.

$F_{1}$ seeds germinated in paper cups were grown in the laboratory till three-leaf stage and then transferred to pots. We obtained $F_{1}$ seeds from 36 crosses, designated as SM1-SM36. Panicles in $F_{1}$ plants were covered with paper bags to allow self-pollination and $F_{2}$ seeds were harvested at maturity. $F_{2}$ plants were grown in the field and morphological traits were recorded during the rainy season of 2010. These progenies were further advanced through single plant/panicle selection. We selected 266 lines in the $\mathrm{F}_{4}$ generation that were agronomically interesting. Plant progenies from the above lines were evaluated in the field during two crop seasons, rainy and post-rainy, in augmented design along with elite genotypes as checks SSV84, SSG59-3, 2219 and M35-1. Traits such as plant height, days to $50 \%$ flowering, tiller number, panicle length and width, and brix content in stalk juice were evaluated using SAS statistical software.

\section{Molecular analysis}

In the first set of experiments, maize parent (CM211), sorghum parent (27B), along with two advanced derivatives from these lines, viz. SM2094 (has a large panicle with good seed yield per panicle) and SM2114 (a high biomass line with sweet juicy stalk) were analysed using 24 RAPD markers. Genomic DNA isolation was done using GeNei Plant DNA extraction kit. PCR reaction was set up using genomic DNA $~ 30 \mathrm{ng}$, DNTP mix $(2.5 \mathrm{mM}$ each) $1.5 \mu \mathrm{l}$, random primer $100 \mathrm{ng}$, Taq DNA polymerase assay buffer A $(10 \times) 1 \times$, Taq DNA polymerase enzyme $1.5 \mathrm{U}$ to a total reaction mixture of $25 \mu \mathrm{l}$ with reaction cycles as $94^{\circ} \mathrm{C}, 5 \mathrm{~min} .94^{\circ} \mathrm{C}, 45 \mathrm{sec}, 35^{\circ} \mathrm{C}, 1 \mathrm{~min}$, $72^{\circ} \mathrm{C}, 2 \mathrm{~min}, 72^{\circ} \mathrm{C} 10 \mathrm{~min}$ and $4^{\circ} \mathrm{C}$ storage. Then $15 \mu \mathrm{l}$ of PCR products was loaded onto $1.8 \%$ agarose gel and resolved by electrophoresis. The gel was subsequently stained with ethidium bromide and viewed under UV light.

In another set of experiments, DNA was isolated from 25 genotypes (six parents and 19 early flowering derivatives) using the modified CTAB method. PCR was performed using 26 sorghum SSR markers on different chromosomes with reaction mixture $(20.0 \mu \mathrm{l})$ containing $50-100 \mathrm{ng}$ of template DNA, $2.0 \mu \mathrm{l}$ of $10 \times$ buffer containing $15 \mathrm{mM} \mathrm{MgCl}_{2}, 0.05 \mathrm{mM}$ dNTP, $0.75 \mathrm{pM}$ primers and 0.6 units Taq DNA polymerase (Invitrogen, USA). Amplification was carried out using a thermocylcer (MJ Thermal Cycler, USA) with one cycle at $94^{\circ} \mathrm{C}$ for $5 \mathrm{~min}$ (initial denaturation), followed by 40 cycles of $95^{\circ} \mathrm{C}$ for $30 \mathrm{sec}$ (denaturation), $57^{\circ} \mathrm{C}$ for $30 \mathrm{sec}$ (annealing), and $72^{\circ} \mathrm{C}$ for $1 \mathrm{~min}$ (extension). The amplified products were separated on $2.0 \%$ agarose gel (Sigma, USA). The resulting amplification was recorded as 0 (band not present) and 1 (band present).

\section{Scoring and data analysis}

Bands were scored as present (1) or absent (0) at each band position for all 26 primers. These primers used were assessed using two indices, diversity index (DI) and Rp (resolving power).

\section{Similarity matrix and cluster analysis}

All numerical taxonomic analyses were conducted using the software package DARwin 6. Data from all the 26 primers were pooled to get one similarity matrix for deriving relationships among and within accessions. The matrix of similarity coefficients was subjected to cluster analysis and tree construction through neighbour joining.

\section{Results}

Sorghum parental lines from diverse cytoplasmic backgrounds, viz. MS1, MS2, MS3 and MS4 were used as female parents. Lines 27, 126, 296 and 356 were based on $\mathrm{A}_{1}$ cytoplasm, while MR750, C43 were based on $\mathrm{A}_{2}$ cytoplasm. Parent 748 was based on $\mathrm{A}_{3}$ cytoplasm and $\mathrm{A}_{4} 9$ was based on $\mathrm{A}_{4}$ cytoplasm. Initially, pollen germination of maize lines was standardized using four different pollen germination media (PGM1-PGM4). PGM1 and PGM4 showed less number of grains germinating and also the length of pollen tube was short. PGM3 showed higher percentage of germination and long pollen tubes, while PGM2 was the best medium to induce high percentage germination as well as longest pollen tubes (Figure 1). Maize inbred line CM211 was used for many crosses as it showed the highest pollen germination percentage, as well as rapid and long pollen tube growth. Among 43 sorghum panicles pollinated, $\mathrm{F}_{1}$ seed set was observed in $30(69.8 \%)$ panicles; there was no seed set in seven panicles and in six panicles enlarged ovaries were observed (Table 1, Figure 2). Seed set ranged from $0 \%$ to $40 \%$ with a mean of $4.3 \%$ florets. Among cytoplasmic backgrounds, $\mathrm{A}_{2}$ cytoplasm showed highest seed set. Parental lines 27A and 126A had set seeds with all the four maize inbred lines among nine sorghum parents. In some of the crosses complete development of seed was lacking, but we observed enlarged ovaries in $296 \mathrm{~A}_{1}, \mathrm{~A}_{2} 7$, $\mathrm{A}_{3} 8$ and $\mathrm{A}_{4} 9$ genotypes (Figure 2). Such enlargement of ovaries was not observed in control plants, which were not pollinated. All the seeds resembled sorghum, some 


\section{RESEARCH ARTICLES}

were normal and others deformed (Figure 2). Survival of $F_{1}$ plants after transplantation to pots was far less than control. Forty-five per cent of $F_{1}$ seeds gave rise to fully grown plants. Out of total $1849 \mathrm{~F}_{1}$ seeds harvested 1288 $(69.6 \%) F_{1}$ plants grew completely. Plant height varied among $\mathrm{F}_{1}$ plants derived from the same cross (Figure $3 a$ ), $4.2 \%$ of $\mathrm{F}_{1}$ plants were shorter than their parents, while $22.8 \%$ were taller than their parents and $73 \%$ resembled their parents. Among these $\mathrm{F}_{1}$ plants only 36 (2.7\%) had set seeds and the crosses were designated as SM1-SM36 (Table 2). Notable phenotype variation in the $F_{2}$ progeny was observed in eight crosses, viz. SM1, SM6, SM17, SM18, SM19, SM26, SM27 and SM32. Many others were sterile.

Large variation for morphological traits in $\mathrm{F}_{2}$ included plant height (many tall types compared to sorghum parents), pollen fertility, leaf shape and colour (Figure $3 b$ ), seed size, shape and colour, days to flowering, length and panicle morphology (Figure $3 c$ and $d$ ). Sorghum parents were not pigmented throughout the life cycle, but the maize parents were pigmented. Some of the $F_{1}$ and $F_{2}$ progeny plants showed pigmentation. Progeny derived from 27A and CM211 (SM6) showed leaf types close to maize. Figure 4 shows comparative leaf anatomy of sorghum and maize parents and the hybrid. Stomata in sorghum leaf epidermis were scattered, and the guard cells appeared broad and flat. In maize the stomata were aligned in rows and guard cells were bell-shaped. In the sorghum $\times$ maize derivative plants, the stomata were aligned in rows like maize and the shape of the guard cells was between that of sorghum and maize (Figure 4). There was large variation for plant types in four crosses, viz. SM1, SM6, SM27 and SM30. Very tall $(455 \mathrm{~cm})$ and thick stem resembling sweet sorghum was observed. A few of them had multiple tillers with loose panicles resembling forage sorghum types and some others flowered very early at 45-55 days (Supplementary Tables 1 and 2).

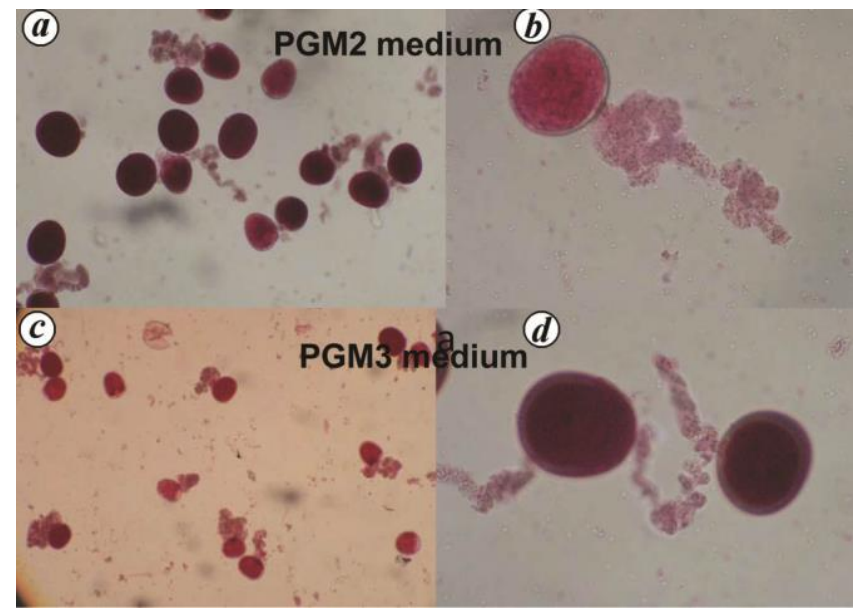

Figure 1. Induction of pollen germination in maize with pollen germination media, PGM2 and PGM3. $\boldsymbol{a}-\boldsymbol{c}$, Number of pollen grains germinated. $\boldsymbol{b}, \boldsymbol{d}$, Length of pollen tube.
Expression of these traits was true in both rainy and postrainy seasons. Derivatives of SM1 and SM6 had bold and lustrous grains like the best grain type of India, viz. M351. Stable lines in $\mathrm{F}_{4}$ were selected and plant type specific traits were studied for one rainy and one post-rainy season in the field in augmented design along with checks. Based on the trait expression the lines were recategorized as early flowering, forage, sweet sorghum and grain type. Table 3 shows the parents of the trait-specific lines.

\section{Sweet sorghum types}

Among $266 \mathrm{~F}_{4}$ lines, 134 lines showed tall, thick stems with sweet, juicy stalks compared to sweet sorghum check SSV84. Among them, 27 were promising for their brix content. These are the progenies of four crosses, viz. SM6, SM27, SM30 and SM32 (Table 3). These plants had broad and long leaves. Analysis of stalk juice showed that nine lines contained high total sugars $12-20 \%$ compared to $17.7 \%$ in SSV84. Reducing sugars were low (8.6-2.1\%) compared to sweet sorghum check genotype SSV84 (8.7\%). Two lines, viz. 2289-4 and 2289-9 had all the desirable traits such as high brix, high total soluble sugars (TSS), high percentage of sucrose and low percentage of reducing sugars (RS).

\section{Forage types}

Twenty-five lines showed forage traits such as multiple tillers, narrow leaves and loose panicles. Fifteen of them were promising compared to the forage check SSG59-3. These were derived from the crosses SM1, SM6, SM12, SM27, SM30 and SM32 (Table 3).

\section{New morphological types}

Leaf morphotypes such as purple leaves, purple leaf margin like maize, broad leaves and wrinkled leaf surfaces were identified (Figures $3 b$ and 4).

Table 1. Seed set in sorghum $\times$ maize pollinations

\begin{tabular}{|c|c|c|c|c|}
\hline \multirow[b]{2}{*}{ Sorghum as female parent } & \multicolumn{4}{|c|}{ Maize as pollinator parent } \\
\hline & CM118 & CM130 & CM208 & CM211 \\
\hline $27 \mathrm{~A}$ & $\bullet$ & & $\bullet \bullet$ & $\bullet \bullet$ \\
\hline 296A & $\diamond$ & & $\diamond$ & \\
\hline $126 \mathrm{~A}$ & $\bullet \bullet \bullet$ & & $\bullet \bullet \bullet$ & $\bullet \bullet \bullet$ \\
\hline $356 \mathrm{~A}$ & $\bullet$ & $\bullet$ & & $\bullet \bullet \bullet \bullet$ \\
\hline $\mathrm{C} 43 \mathrm{~A}_{2}$ & $\diamond$ & 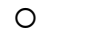 & $\mathrm{O}$ & $\bullet \bullet \bullet \bullet$ \\
\hline $\mathrm{A}_{2} 7$ & & & & $\bullet$ \\
\hline $\mathrm{MR} 750 \mathrm{~A}_{2}$ & $\bullet$ & & $\bullet \bullet$ & $\bullet$ \\
\hline $\mathrm{A}_{3} 8$ & O & O & & $\bullet \bullet$ \\
\hline $\mathrm{A}_{4} 9$ & O & & 0 & $\diamond$ \\
\hline
\end{tabular}

$\diamond$, Enlarged ovules; •, Normal seed; O, No seed. 
RESEARCH ARTICLES

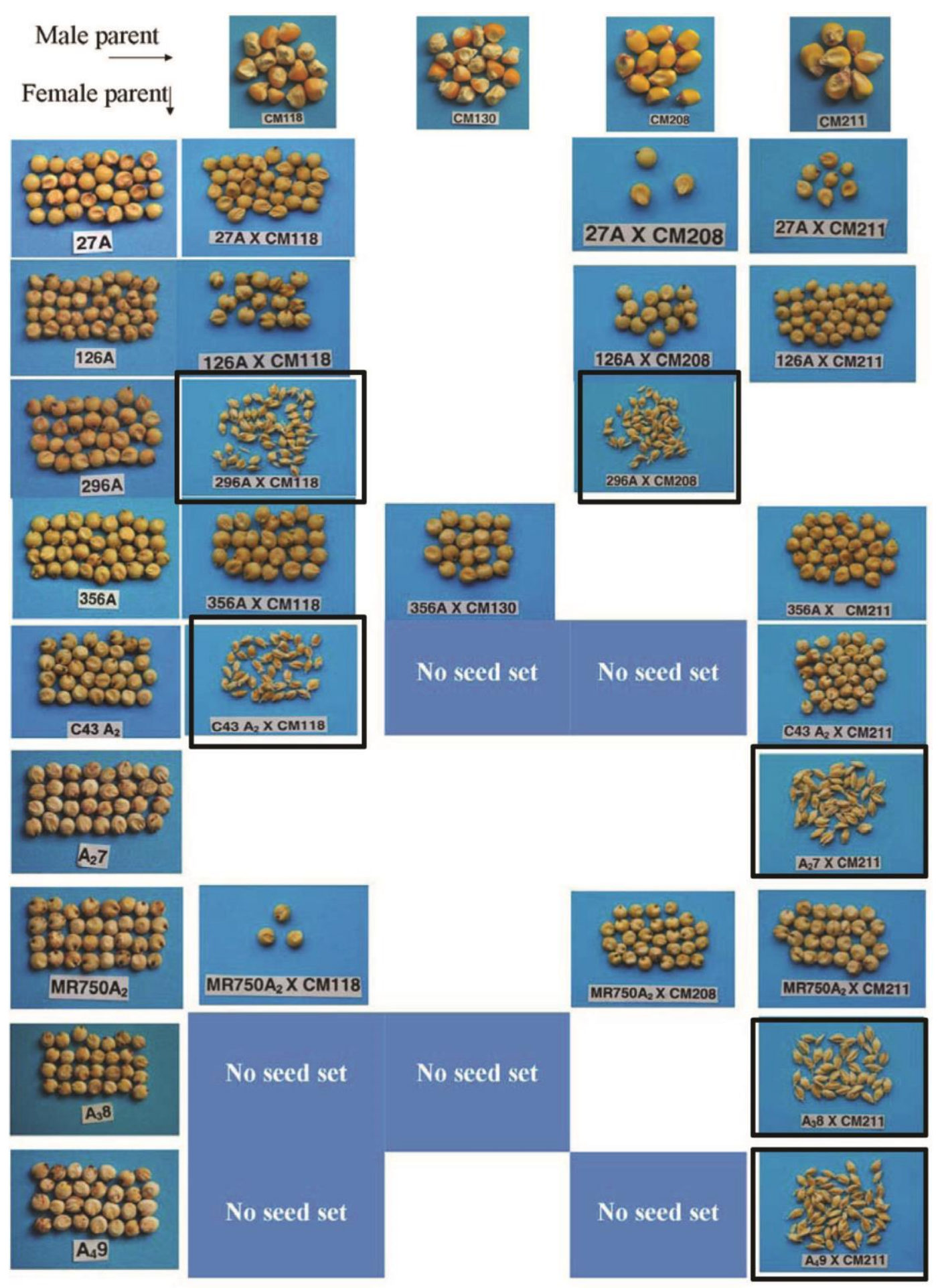

Figure 2. Seed set in inter-generic pollination - maize pollinated on sorghum. Box enclosures are enlarged ovaries.

\section{Early flowering types}

Ten lines flowered as early as check genotype 2219 and were derived from SM1, SM6, SM27 and SM30. These formed a district cluster from elite parental lines in the molecular analysis (Figure 6).

\section{Grain types}

Eighteen genotypes had desirable grain characters of size, colour and luster with a long panicle. In a single line, viz. 2094, derived from $27 \times$ CM211 (SM6), many colours were observed. Colour of the glumes varied from white to 


\section{RESEARCH ARTICLES}
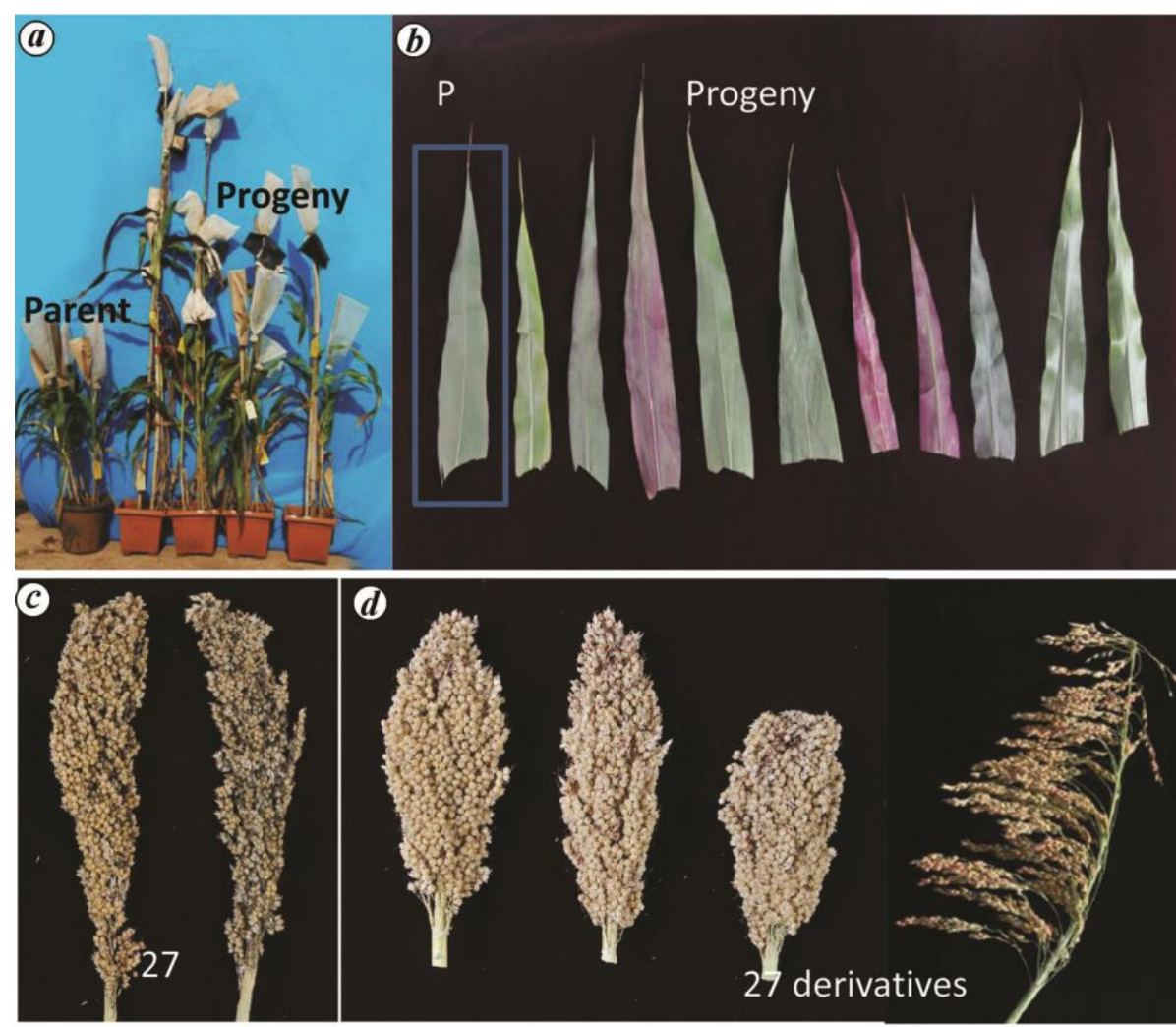

Figure 3. $\boldsymbol{a}$, Sorghum parent, 27A. Four $\mathrm{F}_{1}$ plants derived from 27A. $\boldsymbol{b}$, Different leaf pigmentation patterns in young leaves (P, parent). $\boldsymbol{c}$, Panicle of 27. $\boldsymbol{d}$, Panicles derived from 27.
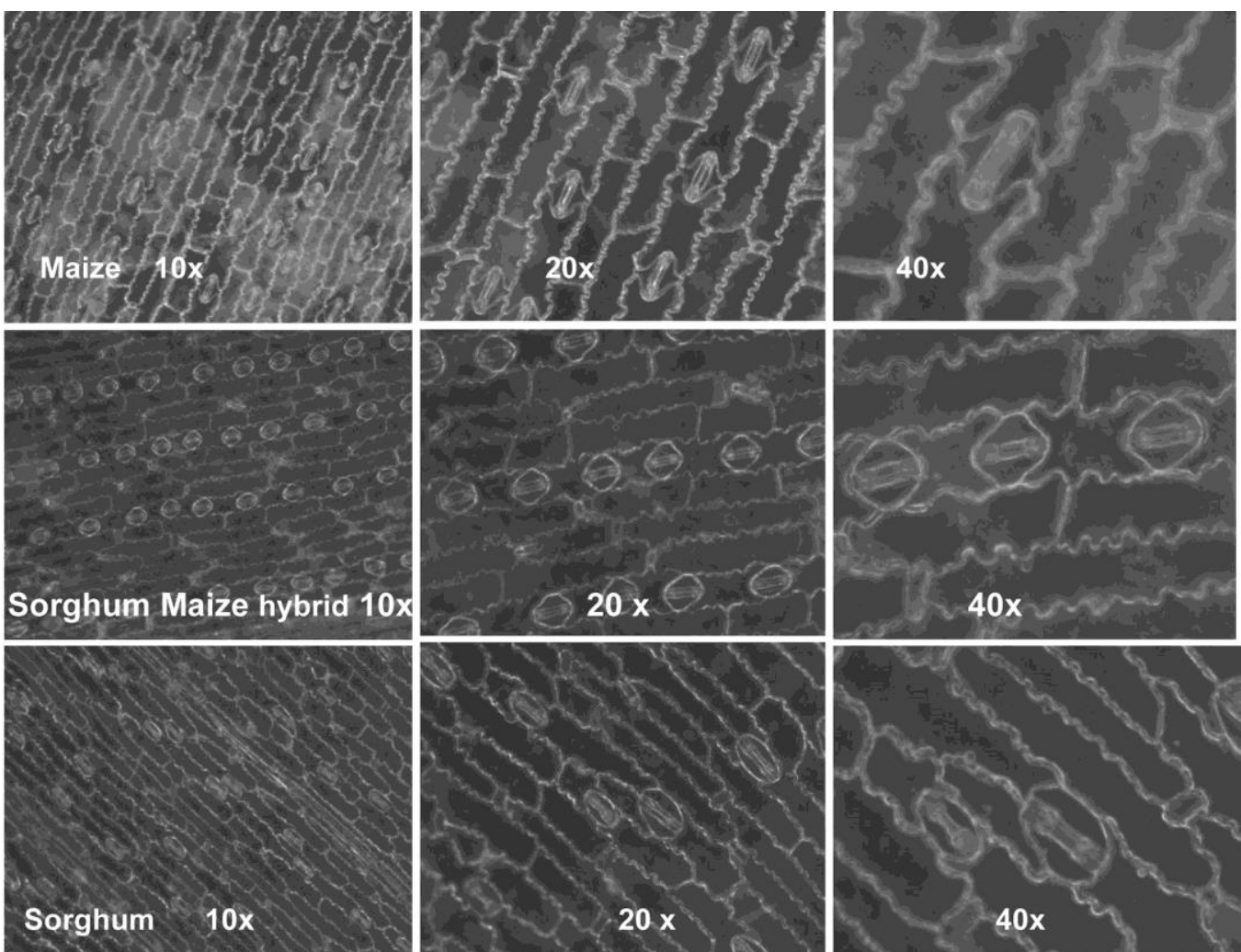

Figure 4. Leaf epidermis in sorghum $\times$ maize derivatives. Sorghum stomata are randomly arranged, guard cells are crescent-shaped. Maize guard cells are arranged in rows and stomata are bell-shaped. Sorghum $\times$ maize leaves are like sorghum, but stomata arrangement and shape resemble maize. 
Table 2. Details of pollination, seed set and $F_{1}$ progeny

\begin{tabular}{|c|c|c|c|c|}
\hline $\begin{array}{l}\mathrm{F}_{1} \text { plant } \\
\text { designation }\end{array}$ & Parents & $\begin{array}{c}\text { Total florets } \\
\text { pollinated }\end{array}$ & $\%$ Seed set & No. of plants survived \\
\hline SM1 & $27 \mathrm{~A} \times \mathrm{CM} 118$ & 1000 & 7.40 & 40 \\
\hline SM2 & $27 \mathrm{~A} \times \mathrm{CM} 118$ & 900 & 0.30 & 0 \\
\hline SM3 & $27 \mathrm{~A} \times \mathrm{CM} 208$ & 1040 & 0.20 & 1 \\
\hline SM4 & $27 \mathrm{~A} \times \mathrm{CM} 208$ & 400 & 0.25 & 1 \\
\hline SM5 & $27 \mathrm{~A} \times \mathrm{CM} 211$ & 570 & 0.90 & 2 \\
\hline SM6 & $27 \mathrm{~A} \times \mathrm{CM} 211$ & 660 & 0.03 & 1 \\
\hline SM7 & $296 \mathrm{~A} \times \mathrm{CM} 118$ & 560 & 53.6 & 0 \\
\hline SM8 & $296 \mathrm{~A} \times \mathrm{CM} 208$ & 460 & 26.95 & 0 \\
\hline SM9 & $126 \mathrm{~A} \times \mathrm{CM} 118$ & 580 & 0.06 & 2 \\
\hline SM10 & $126 \mathrm{~A} \times \mathrm{CM} 118$ & 940 & 1.81 & 16 \\
\hline SM11 & $126 \mathrm{~A} \times \mathrm{CM} 118$ & 1278 & 1.25 & 9 \\
\hline SM12 & $126 \mathrm{~A} \times \mathrm{CM} 208$ & 1060 & 1.32 & 10 \\
\hline SM13 & $126 \mathrm{~A} \times \mathrm{CM} 208$ & 620 & 1.129 & 0 \\
\hline SM14 & $126 \mathrm{~A} \times \mathrm{CM} 208$ & 520 & 0.19 & 1 \\
\hline SM15 & $126 \mathrm{~A} \times \mathrm{CM} 211$ & 630 & 1.11 & 6 \\
\hline SM16 & $126 \mathrm{~A} \times \mathrm{CM} 211$ & 582 & 5.49 & 0 \\
\hline SM36 & $126 \mathrm{~A} \times \mathrm{CM} 211$ & 892 & 0.11 & 1 \\
\hline SM17 & $356 \mathrm{~A} \times \mathrm{CM} 118$ & 2700 & 11.85 & 239 \\
\hline SM18 & $356 \mathrm{~A} \times \mathrm{CM} 130$ & 760 & 2.50 & 17 \\
\hline SM19 & $356 \mathrm{~A} \times \mathrm{CM} 211$ & 1750 & 10.28 & 161 \\
\hline SM20 & $356 \mathrm{~A} \times \mathrm{CM} 211$ & 1550 & 0.32 & 0 \\
\hline SM21 & $356 \mathrm{~A} \times \mathrm{CM} 211$ & 1348 & 15.2 & 54 \\
\hline SM22 & $356 \mathrm{~A} \times \mathrm{CM} 211$ & 2345 & 2.64 & 51 \\
\hline SM23 & $\mathrm{C} 43 \mathrm{~A} 2 \times \mathrm{CM} 118$ & 450 & 0.22 & 0 \\
\hline SM24 & $\mathrm{C} 43 \mathrm{~A} 2 \times \mathrm{CM} 211$ & 2050 & 9.27 & 13 \\
\hline SM25 & $\mathrm{C} 43 \mathrm{~A} 2 \times \mathrm{CM} 211$ & 1950 & 1.28 & 13 \\
\hline SM26 & $\mathrm{C} 43 \mathrm{~A} 2 \times \mathrm{CM} 211$ & 2450 & 1.42 & 13 \\
\hline SM27 & $\mathrm{C} 43 \mathrm{~A} 2 \times \mathrm{CM} 211$ & 3500 & 8.57 & 196 \\
\hline SM28 & $\mathrm{A} 27 \times \mathrm{CM} 211$ & 600 & 15.67 & 0 \\
\hline SM29 & MR750A $2 \times$ CM118 & 510 & 0.59 & 2 \\
\hline SM30 & MR750A2 × CM208 & 2100 & 3.80 & 70 \\
\hline SM31 & MR750A2 × CM208 & 1750 & 0.40 & 40 \\
\hline SM32 & $\mathrm{MR} 750 \mathrm{~A} 2 \times \mathrm{CM} 211$ & 2500 & 16.0 & 326 \\
\hline SM33 & A $38 \times$ CM211 & 155 & 5.80 & 0 \\
\hline SM34 & A $38 \times$ CM 211 & 950 & 0.21 & 2 \\
\hline SM35 & $\mathrm{A} 49 \times \mathrm{CM} 211$ & 210 & 40.00 & 1 \\
\hline
\end{tabular}

black. These lines were promising for popping and equivalent to many elite pop sorghum lines. Grain types were derived from SM1and SM6.

Sorghum parental line 27 produced variants for all the traits (Table 3). MR750, belonging to the $\mathrm{A}_{2}$ cytoplasm was the next promising parent for variation. Sorghum parents C43 and 126A showed variation for flowering early and grain traits.

\section{Molecular analysis}

Parental line 27 is the parent of many popular sorghum hybrids. It is short with a long panicle and good yield. Its advanced derivatives, SM2114 and SM2094, derived from a single cross, viz. SM6, were separated for trait in the $\mathrm{F}_{2}$ generation. SM2114 is a very tall type with thick stems having juicy stalk like sweet sorghum. Another derivative SM2094, is a grain-type plant, medium tall with a heavy compact panicle and has good grain yield. Both the derivatives shared RAPD amplification of DNA with the maize parent as well as the sorghum parent (Figure $5 a-h$ ).
Presence of bands only like maize, but not like sorghum, in the derivatives suggests the gene sequences of maize. In Figure $5 e, f$ and $h$, common bands between maize and SM2094 were seen, but these were absent in SM2114. In Figure $5 g$, common bands between SM2114 and maize parent were seen. These two lines shared common as well as unique bands between them, suggesting their common origin and diversification as early as the $F_{2}$ generation. Early flowering lines derived from two crosses, viz. C43 $\times$ CM211 (2273) and MR750 × CM208 (2275 and 2276) were studied. Cluster analysis identified three groups, all the parental lines and progenies of 2273 and 2275 in one, progenies of 2273 and 2276 in the second and 2276 in the third (Figure 6). Many of the derivatives from the crosses formed a separate cluster indicating their genetic identity from the parents.

\section{Discussion}

Crosses between sorghum and maize did not survive in most of the cases and when they survived, did not bear 
Table 3. Variation of traits and source sorghum, maize parents and $F_{1}$ plants

\begin{tabular}{lllc}
\hline Trait & \multicolumn{1}{c}{ Sorghum parents } & \multicolumn{1}{c}{ Maize parents } & $\begin{array}{c}\text { No of source } \\
\text { F1 plants }\end{array}$ \\
\hline Early flowering & 27A, C43, MR750 & CM118, CM208, CM211 & 4 \\
Sweet sorghum & 27A, MR750 & CM208, CM211 & 2 \\
Forage & 126A, 27A, MR750 & CM208, CM211 & 4 \\
Grain & 27A & CM118, CM211 & 2 \\
Popping & 27A, MR750 & CM118, CM208, CM211 & 3 \\
\hline
\end{tabular}
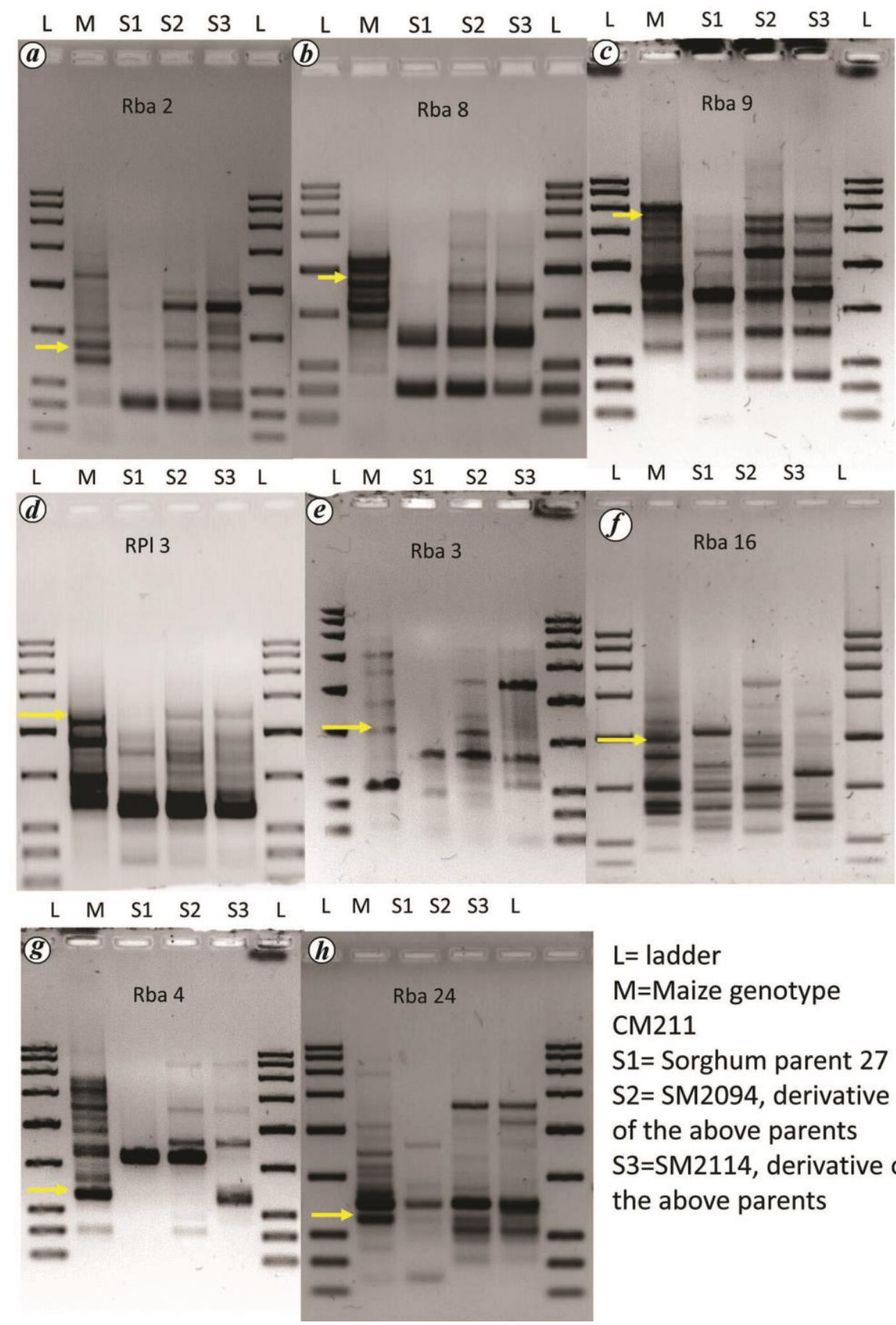

$\mathrm{L}=$ ladder

$\mathrm{M}=$ Maize genotype

CM211

S1= Sorghum parent 27

S2= SM2094, derivative

of the above parents

S3=SM2114, derivative of

the above parents

Figure 5. RAPD analysis of advanced lines from the cross 27 (sorghum) and CM211 (maize). 


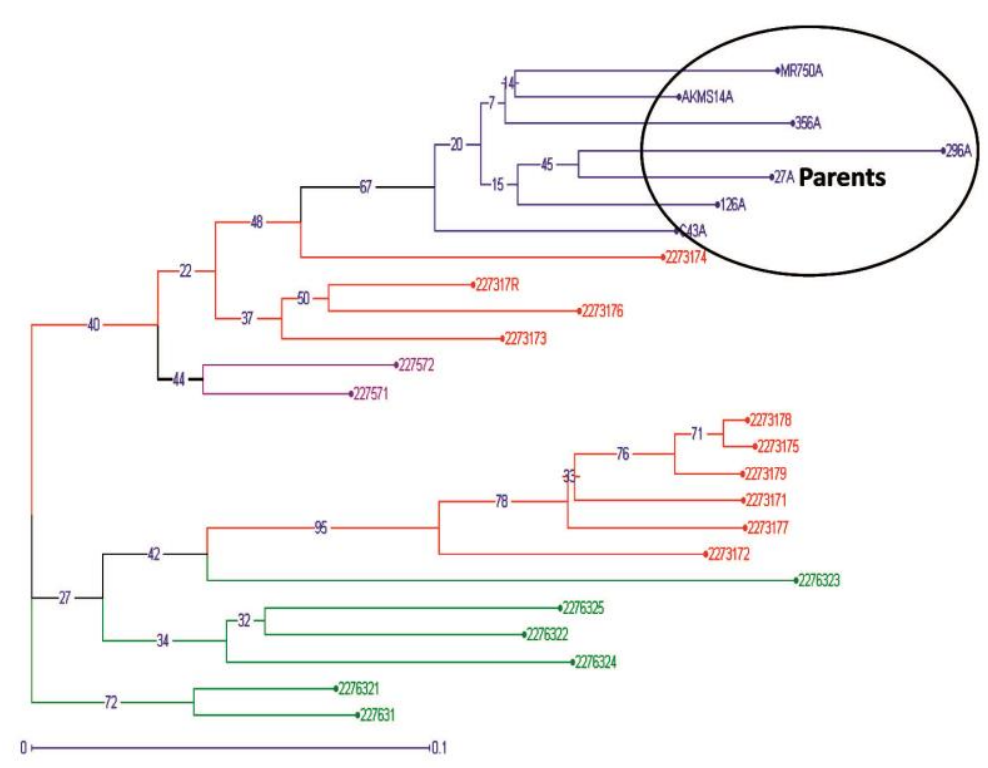

Figure 6. Cluster diagram of early flowering derivatives from four crosses along with parents.

the inflorescence. Gerrish ${ }^{6}$ developed shrivelled seeds that gave rise to maize-like plants without inflorescence. All these reports were restricted to $F_{1}$ seeds and plants, and none had been extended to $F_{2}$ generation and beyond. The goal of inter-generic hybridization is to develop ready-to-use pre-breeding material for crop improvement programmes. Hence, we pursued sorghum $\times$ maize crosses to further generations in the interest of developing prebreeding material and could successfully generate prebreeding material of different types in sorghum.

Lack of germination of maize pollen and failure to reach the micropyle and ovule are the reasons for failure of hybridization between sorghum and maize ${ }^{7}$. Pollination with pre-germinated pollen is useful in overcoming pollen pistil barriers in sorghum ${ }^{8}$, which was also used in the present study. There were enlarged ovaries failing to develop into seeds, a phenomenon absent in unpollinated florets. An interaction of nuclei of sorghum and maize may have led to complete seed development, while only the entry of pollen tube without nuclear interaction may have stimulated ovaries?.

Rice was pollinated by unrelated and incompatible dicot species, the Oenothera, which resulted in mutant phenotypes in similar lines to our SM6-derived population$^{2}$. In many other incompatible crosses also, the $F_{1}$ plants did not display the expected hybrid pattern and resembled the female line leading to the conclusion that the crosses had failed until the $F_{2}$ generation was studied $^{10}$. In the present study, $\mathrm{F}_{1}$ plants resembled sorghum, but the $F_{2}$ progeny showed unpredictable diversity. Intergeneric pollinations are reported to cause several genomic, epigenomic and transcriptomic variations in the progeny that result in novel phenotypes ${ }^{1-5}$. Cryptic alien introgression as small as less than $0.1 \%$ was found to affect $30 \%$ of the genomic loci in the recombinant inbred lines (RILs) derived from incompatible crosses in rice ${ }^{12}$. This explains the vast variation from the cross SM6 that was reflected in the RAPD analysis. We consider that the maize genetic material is eliminated to a large extent and the residual maize genetic components in sorghum remaining after incomplete elimination have disturbed the genome leading to genome shake resulting in large variation. The intergeneric cross between distant species, Chrysanthemum morifolium and Leucanthemum paludosum induced rapid changes at the genetic and epigenetic levels involving loss of parental fragments and gaining of novel fragments ${ }^{11}$. Combining such diverse genomes into a single nucleus can be expected to cause genomic shock in terms of alteration in the pattern of DNA methylation. A small amount of Zizania-specific DNA was found in the rice-Zizania introgression lines, while there was no introgression of maize genomic DNA fragments in the rice-maize introgression line MU1, but large variation was induced in both ${ }^{3,12}$. Similar observations have been reported for three introgressed lines obtained using repeated pollination procedures of rice lines with incompatible Zizania latifolia ${ }^{1}$. A single rice mutator-phenotype individual (Tong211-LP) with conspicuous variation due to transgenerational epigenetic/genetic variation-induced by alien pollen in multiple phenotypic traits was identified in a cross between rice and Oenothera biennis $\mathrm{L}^{2}$. Pollination of rice with maize resulted in an agronomically superior and stable line as a result of many genomic and transcriptomic alterations ${ }^{3}$. Molecular analysis of such variation was related to changes in DNA methylation patterns and retrotransposon activation in such introgressed rice lines ${ }^{13}$. Promising novel and important germplasm lines resulted due to genetic and epigenetic alterations of DNA through alien introgression in Brassica after intertribal hybridization ${ }^{14}$. Bombom ${ }^{15}$ reported 
successful cross between sorghum and maize yielding fertile $F_{1}$ generation. His observations corroborate our results regarding variation among $F_{1}$ progeny and segregation among $F_{2}$ progeny for the number of characteristics, including plant vigour and grain size.

Intergeneric crossing barriers between Carica papaya var. Surya and Vasconcellea cauliflora were broken down using sucrose treatment and progenies were raised ${ }^{16}$. We employed pretreatment of pollen and repeated pollination that facilitated pollen entry and seed set. In this study, we started pollination before the flower buds were open in order to acclimatize the sorghum with maize pollen so that it is not treated as alien. The present study on pollination of sorghum with maize has implications for breeding purposes through introduction of large genetic diversity.

In this study, SM6 $(27 \mathrm{~A} \times \mathrm{CM} 211)$ showed all the types of variants in $\mathrm{F}_{2}$ generation, some of them being stable and others not. All the sorghum parents were short and grain type, some of the derivatives were forage and sweet sorghum type that are found superior for the trait in multilocation field trials ${ }^{17,18}$. Knowledge about the genome-wide genetic variation among forage, sweet and grain sorghum and potential genome regions and metabolic pathways associated with these traits provides insight not only to designer crops but also about the regulation of metabolic pathways in creating diversity. It may be interesting to see whether we can use incompatible crosses for the introduction of novel variation in crops species.

\section{Conclusion}

Repeated pollination of sorghum with maize gave rise to large de novo variations that were stable and agronomically superior ready-to-use pre-breeding lines. Molecular analysis of diverse sorghum $\times$ maize derivatives revealed maize DNA fragments. Dendrogram showed the distinctness of early flowering derivatives from current elite parental lines. Intergeneric pollination provides interesting material for the study of gene expression analysis. This variation can be used in crop improvement programmes.

Conflict of interest: The author declares no conflict of interest.

1. Liu, B., Piao, H. M., Zhao, F. S., Zhao, J. H. and Zhao, R., Production and molecular characterization of rice lines with introgressed traits from a wild species of Zizania latifolia Griseb. J. Genet. Breed., 1999, 53, 279-284.

2. Wang, H. et al., Molecular characterization of a rice mutatorphenotype derived from an incompatible cross-pollination reveals transgenerational mobilization of multiple transposable elements and extensive epigenetic instability. BMC Plant Biol., 2009, 9, 63.

3. Meng, W.-L., Zhao, M.-J., Yang, X.-B., Zhang, A.-X., Wang, N.-N., Xu, Z.-S. and Ma, J., Examination of genomic and transcriptomic alterations in a morphologically stable line, MU1, generated by intergeneric pollination. Genes, 2020, 11, 199.

4. Pachakkil, B. et al., Cytogenetic and agronomic characterization of intergeneric hybrids between Saccharum spp. hybrid and Erianthus arundinaceus. Sci. Rep., 2019, 9, 1748.

5. Chang, H. et al., Production, identification and characterization of Erianthus rockii $\times$ Narenga porphyrocoma intergeneric hybrids as a new germplasm for sugarcane breeding and genetic research. Sugar Technol., 2020, 22, 389-395.

6. Gerrish, E. E., Survey of attempts to cross maize with sorghum. Maize Newsl., 1967, 41, 26-28.

7. Laurie, D. A. and Bennett, M. D., Genetic variation in sorghum for the inhibition of maize pollen tube growth. Ann. Bot., 1989, 64, 675-681.

8. Visarada, K. B. R. S., Overcoming interspecific barriers in sorghum and molecular characterization of the derivatives. Plant Breed., 2020, 1-14; doi:org/10.1111/pbr12831.

9. Bernard, S. and Jewell, D. C., Crossing maize with sorghum, Tripsacum and millet: the products and their level of development following pollination. Theor. Appl. Genet., 1985, 70, 474-483.

10. Faure, N., Serieysm, H., Cazaux, E., Kaan, F. and Bervillé, A., Partial hybridization in wide crosses between cultivated sunflower and the perennial Helianthus species H. mollis and H. orgyalis. Ann. Bot., 2002, 89, 31-39.

11. Wang, H. et al., Rapid genetic and epigenetic alterations under intergeneric genomic shock in newly synthesized Chrysanthemum morifolium $\times$ Leucanthemum paludosum hybrids (Asteraceae). Genome Biol. Evol., 2014, 6, 247-259.

12. Wang, Y. M., Dong, Z. Y., Zhang, Z. J., Lin, X. Y., Shen, Y., Zhou, D. and Liu, B., Extensive de novo genomic variation in rice induced by introgression from wild rice (Zizania latifolia Griseb.). Genetics, 2005, 170, 1945-1956.

13. Liu, B. and Wendel, J. F., Retrotransposon activation followed by rapid repression in introgressed rice plants. Genome, 2000, 43, 874-880.

14. Zhang, X., Ge, X., Shao, Y., Sun, G. and Li, Z., Genomic change, retrotransposon mobilization and extensive cytosine methylation alteration in Brassica napus introgressions from two intertribal hybridizations. PLoS ONE, 2013, 8, e56346.

15. Bombom, A., Conducts research about crop enhancement of maize and sorghum. Tel Aviv University, Israel, 2014; https://foodsecurity.tau.ac.il/news/bombom.

16. Dinesh, M. R., Rekha, A., Ravishankar, K. V., Praveen, K. S. and Santosh, L. C., Breaking the intergeneric crossing barrier in papaya by using sucrose treatment. Sci. Hortic., 2007, 114, 33-36.

17. Visarada, K. B. R. S., Sanjana Reddy, P. and Venkateswarlu, R., Performance of sorghum-maize interspecific derivatives for forage attributes. Agric. Update (TECHSEAR 9), 2017, 12, 23412346.

18. ICAR-IIMRE, Annual Report 2017-18, ICAR-Indian Institute of Millets Research, Hyderabad, 2018, p. 164.

ACKNOWLEDGEMENTS. I thank the Indian Council of Agricultural Research, New Delhi for support; Dr V. A. Tonapi (Director) for encouragement, and Mr J. Narasimha and S. Santosh for helping during field experiments.

Received 24 May 2017; accepted 2 June 2020

doi: $10.18520 / \mathrm{cs} / \mathrm{v} 119 / \mathrm{i} 9 / 1540-1548$ 